\title{
Pierre Bergounioux, sous la direction d'Yves Reboul et de Guy Larroux
}

\section{Enrico Bonadei}

\section{Q OpenEdition}

1 Journals

\section{Edizione digitale}

URL: http://journals.openedition.org/studifrancesi/6442

DOI: $10.4000 /$ studifrancesi.6442

ISSN: 2421-5856

\section{Editore}

Rosenberg \& Sellier

\section{Edizione cartacea}

Data di pubblicazione: 1 novembre 2010

Paginazione: 592-593

ISSN: 0039-2944

\section{Notizia bibliografica digitale}

Enrico Bonadei, «Pierre Bergounioux, sous la direction d'Yves Reboul et de Guy Larroux», Studi Francesi [Online], 162 (LIV | III) | 2010, online dal 30 novembre 2015, consultato il 14 janvier 2021. URL: http:// journals.openedition.org/studifrancesi/6442 ; DOI: https://doi.org/10.4000/studifrancesi.6442

Questo documento è stato generato automaticamente il 14 janvier 2021.

\section{(c) (i) (9)}

Studi Francesi è distribuita con Licenza Creative Commons Attribuzione - Non commerciale - Non opere derivate 4.0 Internazionale. 


\title{
Pierre Bergounioux, sous la direction d'Yves Reboul et de Guy Larroux
}

\author{
Enrico Bonadei
}

\section{NOTIZIA}

Pierre Bergounioux, sous la direction d'Yves REBOUL et de Guy LARROUX, «Littératures», 60, 2009 , pp. 247.

1 Il sessantesimo numero di «Littéraures» (Toulouse, Presses Universitaires du Mirail) è interamente dedicato all'opera di Pierre Bergounioux. Gli articoli presentati tentano, riuscendovi solo parzialmente, di svincolare la figura dell'autore dalla frettolosa definizione di testimone nostalgico e ritirato dal mondo di una «ruralité disparue» (p. 5).

2 Comincia Sylvie DUCAS con Posture de l'écrivain en sa bibliothèque ou la confrérie littéraire de Pierre Bergounioux (pp.11-27), in cui viene esplorato il rapporto complesso che lega lo scrittore alla sua biblioteca «imaginaire et matérielle» (p. 12), secondo i vari rapporti di filiation e confrérie, a seconda che si tratti di modelli del passato o colleghi contemporanei. L'opera di Bergounioux sembra così emergere dalla lotta inconciliabile tra estremi opposti: ammirazione di un passato inimitabile e necessità di affermare se stesso, vita e opera, parola e silenzio.

3 Jean-Yves LAURICHESSE rilegge La Toussaint nell'articolo Faire avec les morts (pp. 29-42), sottolineando come l'autore, nell'invenzione di due paesi e paesaggi immaginari rappresentanti le opposte influenze materna e paterna, riesca a concretizzare la genealogia trasformandola in geografia. A fronte di una tendenza a concretizzare che si ripercuote in profondità nella sua prosa, lo scrittore avvista nella via immateriale della letteratura l'unica possibilità per «devenir soi» (p. 39).

4 Aurélie ADLER in Le Travail de l'empreinte (pp. 43-53) sottopone il testo di L'Empreinte ad una raffinata e profondissima analisi stilistica, al fine di sviscerare le paradossali contraddizioni che muovono l'autore al continuo confronto con il proprio passato. 
Guy LARRoux intitola Maux, remèdes, issues (pp. 55-67) l'analisi del rapporto doloroso che lega l'autore ai luoghi in cui vive, la sua topophobie (p.55). Il male oscuro di Pierre Bergounioux si spiega con la sua incapacità di aderire al tempo in cui vive e con la sfiducia che nutre nei confronti di ogni intervento positivo di cambiamento - per cui i rimedi e le evasioni che escogita sono astratti e inattuabili.

6 Sylvie VIGNeS in La Narration dans "Miette": le modèle de Douglas (pp. 69-79) stabilisce un parallelo tra la struttura narrativa del romanzo e la crescita degli anelli concentrici nei tronchi degli alberi-il Douglas del titolo è appunto un abete che ha una certa importanza nella narrazione.

7 Ibtissem Bouslama, in La Mort en images ou le «différend ininterrompu» avec le réel dans " $\mathrm{La}$ Mort de Brune" (pp. 81-97), studia il rapporto tra scrittura e pittura nella composizione dell'opera, basandosi sul concetto di transdisciplinarité formulato da Bernard Vouilloux in Langages et arts visuels, per giungere alla conclusione che l'arte gioca per l'autore il ruolo di barriera contro la realtà e la morte.

Olivier BARBARANT in Portrait de l'écrivain en volailler (pp.99-106) rivolge la propria attenzione ad un personaggio secondario di La Mort de Brune in cui ritiene di scorgere un ritratto dell'autore all'opera.

Elisa BRIcco tenta di rispondere alla domanda Pourquoi lire les "Carnets de notes" de Pierre Bergounioux? (pp. 107-122). Vengono elencati quindi gli argomenti favorevoli alla lettura nella sezione «Charme», quelli negativi nella seguente «Anti-Charme», per concludere con un bilancio globalmente positivo nella conclusiva «Recharme».

10 Segue Laurent DEMANZE che, ne La Chambre du lettré (pp. 123-134), rilegge Une chambre en Hollande, opera incentrata sulla figura di Descartes, per giungere ad un'interessante definizione del ritiro dell'intellettuale dal mondo, secondo Bergounioux.

11 Nella sezione conclusiva della raccolta, troviamo l'intervista allo scrittore realizzata da Yves REBOUL (Lorsque nous regardons par-dessus notre épaule, pp. 137-153), in cui si discute di morte del romanzo e scienze umane, oltre a due stralci inediti dai copiosi diari dell'autore: i mesi di luglio 2008 e 2009.

12 Si segnala in conclusione l'edizione aggiornata della bibliografia Études sur la prose française de l'extrême contemporain en Italie et en France, a cura di Matteo Majorano, da poco apparsa presso le Edizioni B.A. Graphis di Bari nella collana «Marges critiques». 